\title{
Natural lip function in wind instrument players
}

\author{
Susanne Fuhrimann, Andres Schüpbach, Urs Thüer and Bengt Ingervall \\ Orthodontic Clinic, University of Bern, Switzerland
}

SUMMARY The lip strength, lip muscle activity, pressure from the lips on the teeth and the morphology of the face and the dentition were studied in professional wind instrument players. Twelve trumpeters and twelve clarinetists, aged 19-55 years, were compared with a control group of dental students.

The lip strength was measured with a dynamometer. Electromyographic measurements of the lip muscle activity and recordings of the pressure from the lips on the front teeth were made in the rest position, during chewing and speech and during playing of the instrument. The morphology was studied with $x$-ray cephalometry and on dental casts.

There were practically no differences between the two groups of musicians or in relation to the control group. Thus, the musicians had the same lip strength, the same muscle activity of the lips and the same pressure from the lips on the teeth during natural functions as did the control group. The pressure from the soft tissues on the teeth during playing of the instrument was considerably greater than during natural lip function but no effect on bite morphology was discernible.

\section{Introduction}

The results of recent studies of the effect of lip muscle training are inconclusive. Lip exercises performed by children with incompetent lips were shown to bring about small, positive changes in lip size and lip function but did not affect the tooth position (Ingervall and Eliasson 1982). Training of the lips with an oral screen, on the other hand, did not affect the lip morphology or the natural function of the lips but was shown to increase the strength of the lips (Owman-Moll and Ingervall 1984). It is not known whether the increase in maximal lip strength results in a greater pressure from the lips on the teeth, which might increase the stability of a treatment result.

Wind instrument players provide an opportunity to study the effect of lip muscle training. Professional musicians playing a wind instrument have for many years been using their lips intensively for several hours per day. It seems reasonable to assume that the lip strength of such musicians should be above average. This could also have an effect on the natural function of the lips and the pressure from the lips on the teeth.

This investigation was performed to compare the lip strength and the function of the lips in the rest position, during chewing and during speech of wind instrument players with the same functions in a control group.

Two groups of wind instrument players were chosen, trumpeters and clarinetists, partly on grounds of availability, partly because the lips are used differently in playing these two instruments. When playing the trumpet, both lips are tense (Fig. 1) and vibrate from the stream of air passing between them into the mouthpiece of the trumpet. The clarinet rests on the lower lip, which is positioned over the edges of the lower incisors while the upper lip forms a seal over the upper incisors against the upper part of the mouthpiece (Fig. 2).

\section{Subjects and methods}

Twelve trumpeters and 12 clarinetists took part in the investigation. They were compared with a control group of 12 dental students. The subjects' age and sex distributions are given in Table 1. The musicians were studying at the music school of Bern, Switzerland or had passed their final examination at the school. All were playing their instrument professionally. The only criterion for the selection of the subjects among the musicians and dental students was willingness to participate in the study. 


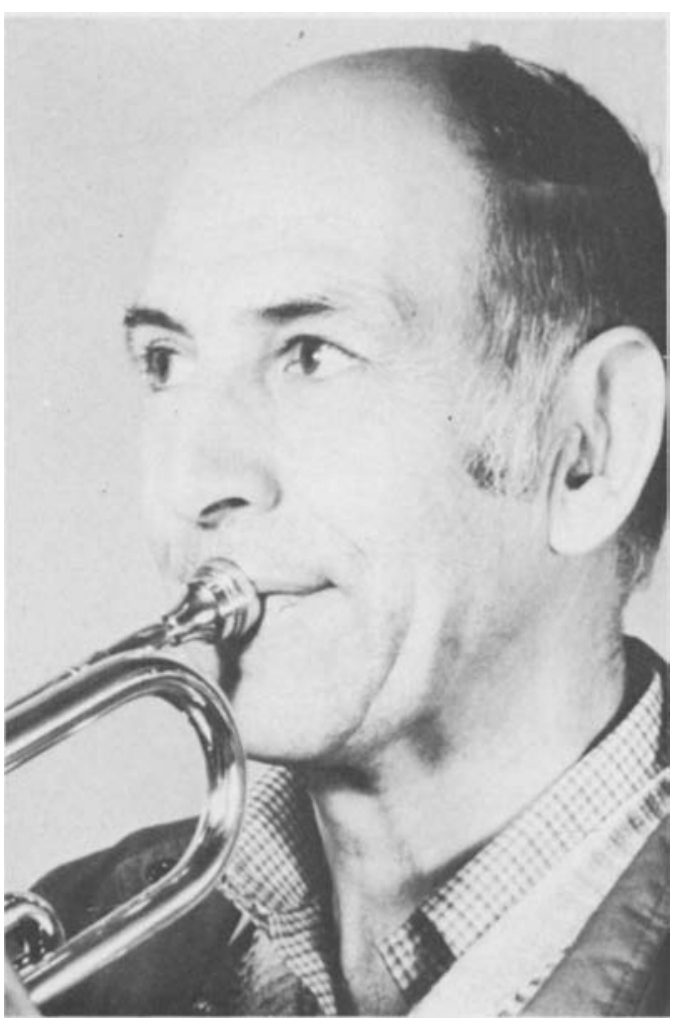

Figure 1 Lip position during playing of the trumpet.

\section{Measurement of lip strength}

The strength of the lips was assessed with a pommeter as described by Posen $(1972,1976)$. The same instrument and method have been used in several investigations by the present authors (see Thüer and Ingervall 1986). The instrument consists of a mouthpiece connected to a dynamometer, which registers a traction force in grams when the mouthpiece is drawn from the lips (Fig. 3). The maximum force is registered in grams, (Pom-value) with which the lips can resist the mouthpiece being pulled loose from the grip between the lips. The median value of nine

Table 1 Age (years) and sex of the subjects studied.

\begin{tabular}{lllll}
\hline & & & \multicolumn{2}{l}{ Age } \\
\cline { 3 - 5 } & Men & Women & Median & Range \\
\hline Trumpeters & 11 & 1 & 27 & $19-55$ \\
Clarinetists & 10 & 2 & 27 & $22-36$ \\
Controls & 11 & 1 & 25 & $23-26$ \\
\hline
\end{tabular}

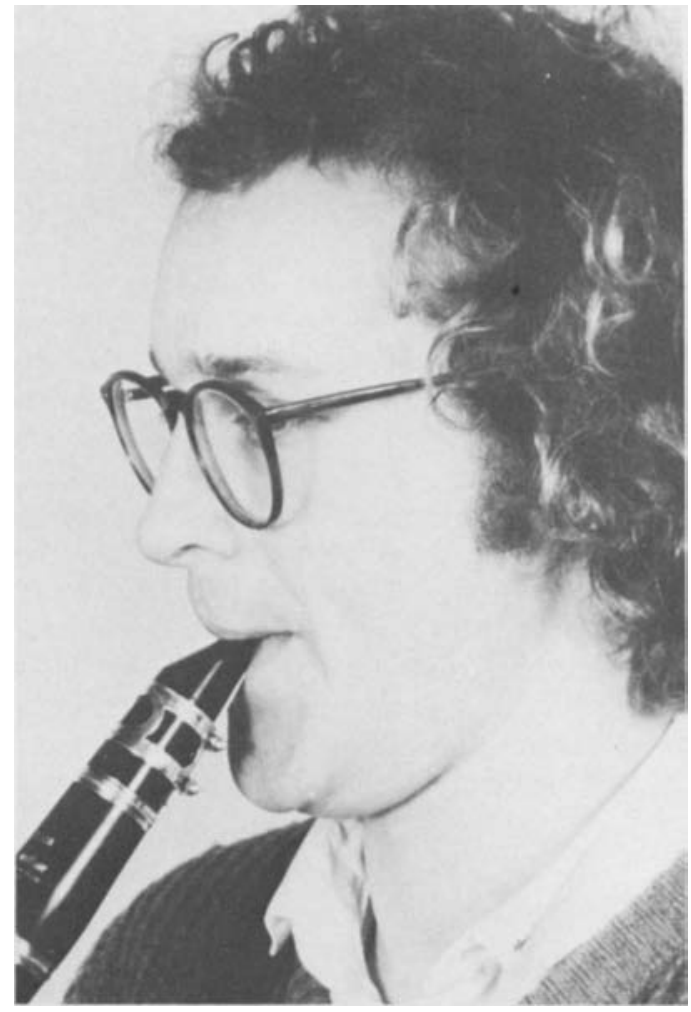

Figure 2 Lip position during playing of the clarinet.

recordings was used as the measurement of lip strength.

\section{Measurement of lip muscle activity}

The state of rest of the lips and their activity during chewing, speech and simulated playing were recorded with a DISA electromyograph. Bipolar hook electrodes (Ahlgren 1967) were in-

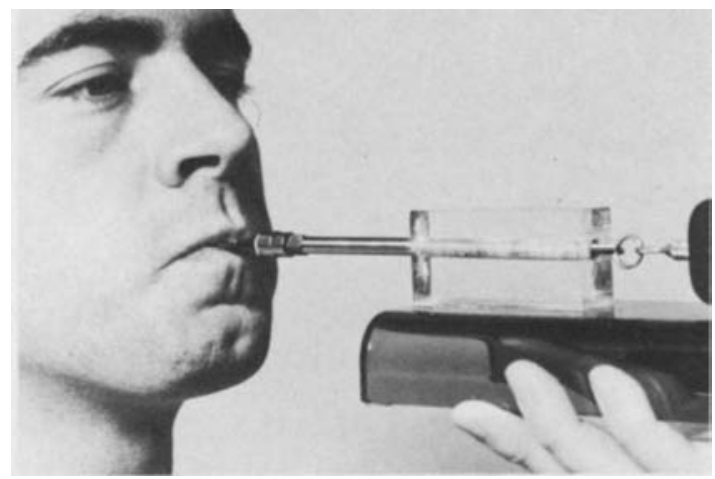

Figure 3 Measurement of lip strength with the pommeter. 
serted $15 \mathrm{~mm}$ apart, $5 \mathrm{~mm}$ above or below the border of the upper and lower red lip, respectively (Fig. 4). A similar electrode was placed as described earlier (Thüer et al. 1985) over the right masseter muscle and was used to ascertain the phase of the chewing cycle.

\section{Measurement of lip pressure}

The pressure from the lips on the teeth was recorded simultaneously with the electromyographic registration in the midline between the upper and lower central incisors (upper and lower lip pressure) and in the right modiolus region (point of measurement in the space between the upper cuspid and first premolar).

The recordings were made with the waterfilled system incorporating an extra-oral pressure transducer described earlier (Thüer et al. 1985, Thüer and Ingervall 1986). As the intraoral measuring point, an open cannula is used which is located buccally, level with the gingival papilla (Fig. 5).

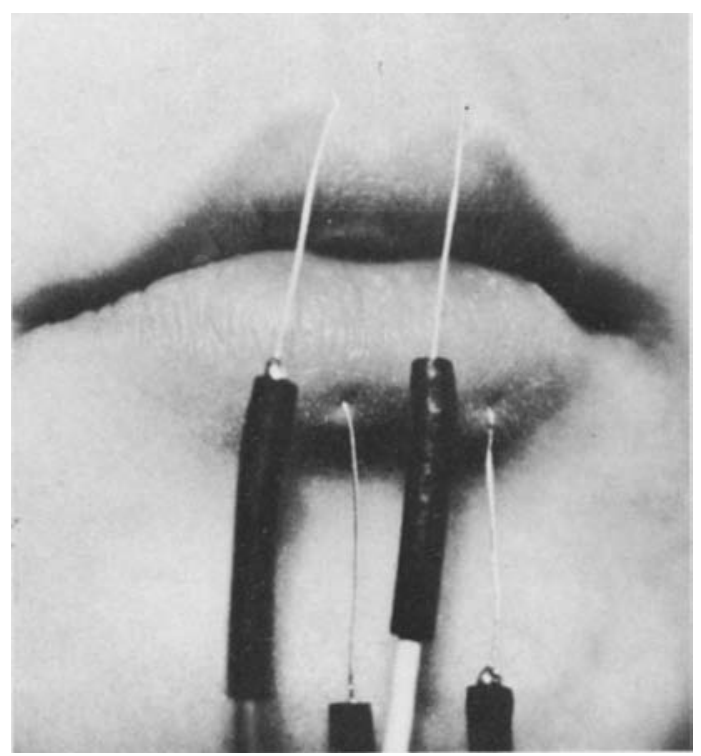

Figure 4 Placement of the electrodes for the recording of lip muscle activity.

The measurements of lip strength, lip muscle activity and lip pressure were made with the same equipment and with the same methods as described in detail earlier (Thüer et al. 1985, Thüer and Ingervall 1986), the only difference being the use of hook instead of surface elec-

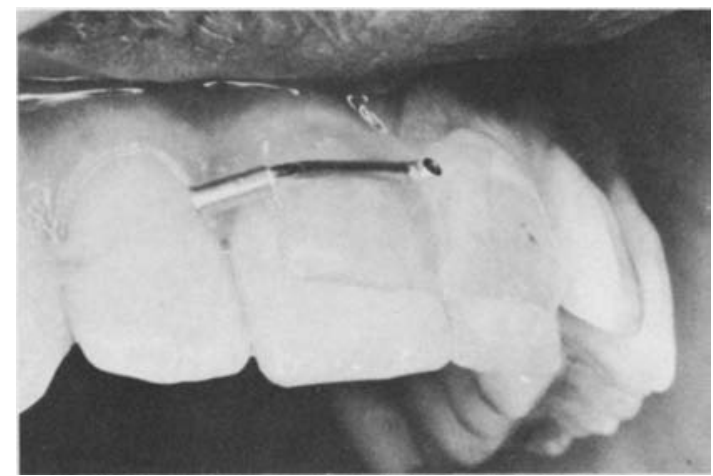

Figure 5 Mouthpiece used for the recording of upper lip pressure.

trodes. This change was necessary because many of the subjects wore a beard or a moustache.

\section{Recording protocol}

(1) Recording of lip strength.

(2) Simultaneous recording of muscle activity (upper and lower lips and masseter) and lip pressure at the upper or lower midline or at the modiolus in random order-

(a) in the rest position of the mandible and lips;

(b) during the chewing of crispbread;

(c) during the articulation of the phrase ' $\mathrm{Oh}$ mein Papa war ein so wunderbarer Mann';

(d) in the musicians during simulation of the playing of the tone ' $a$ ';

(e) new recording in the rest position;

(f) in the musicians during the playing of the tone ' $a$ '.

The resting lip pressure and muscle activity were measured when the electromyographic (EMG) activity was minimal for at least 5 seconds. Two measurements were made at each of the recordings $2 a$ and $2 \mathrm{e}$. The means of these determinations were recorded as lip muscle activity (mean voltage amplitude in $\mu \mathrm{V}$ ) and lip pressure (in grams) in the rest position.

The maximal mean voltage amplitude of the EMG-activity of the upper and lower lips and the maximal lip pressure were determined during the opening and closing phases of the chewing cycle (as judged from the EMG-activity of the masseter muscle). The mean value of 12 randomly selected chewing cycles was calculated. 


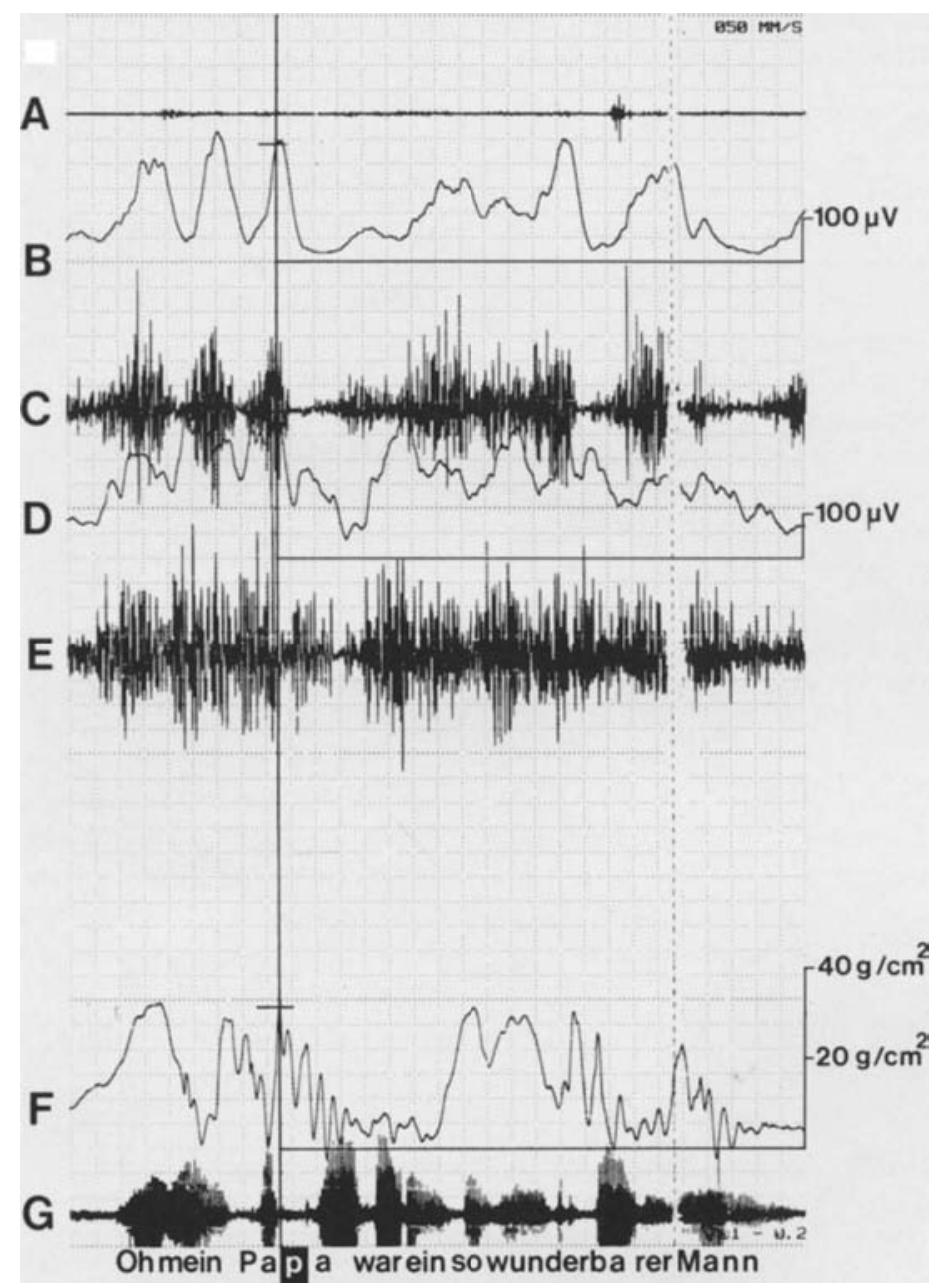

Figure 6 Electromyographic and lip pressure recording of the phrase 'Oh mein Papa war ein so wunderbarer Mann'. A: Direct recording of masseter muscle activity. B: Mean voltage recording of upper lip activity. C: Direct recording of upper lip activity. D: Mean voltage recording of lower lip activity. E: Direct recording of lower lip activity. F: Lip pressure.

The phrase 'Oh mein Papa war ein so wunderbarer Mann' was articulated twice and the lip pressure and lip muscle activity at the second ' $p$ ' in the world Papa were measured (mean of two recordings). To identify the place of measurement the phrase was recorded with a microphone simultaneously with the recording of the lip pressure (Fig. 6). For the recording 2d, the subject tried to hold the lips in a position corresponding to the one he would have used when playing the tone ' $a$ ' on his instrument. The mean voltage activity of the lips and the lip pressure were recorded and measured at 8 points on the paper recording. The mean value was calculated.
In the musicians, the recording of lip pressure during the actual playing of the tone ' $a$ ' was made without the electromyographic electrodes and with either the upper, the lower, or the modiolus pressure-measuring mouthpiece in place. This procedure was used in order to avoid the reinsertion of the electrodes. Thus, four recordings of upper lip pressure, four of lower lip pressure and four of modiolus pressure were made in each of the two groups of musicians. The mean of 8 measurements on the recording strip was calculated.

In order to determine the errors of the method for the recordings of the lip muscle activity 
Table 2 Pom-values in grams as an expression of lip strength.

\begin{tabular}{llrll}
\hline & Mean & S.d. & Median & Range \\
\hline Trumpeters & 318 & 80 & 315 & $200-500$ \\
Clarinetists & 291 & 101 & 270 & $150-430$ \\
Controls & 300 & 106 & 293 & $250-545$ \\
\hline
\end{tabular}

and pressure, they were performed twice in the control group with an interval of $2-6$ months between the two occasions. Only three small systematic differences between the duplicate determinations were found (for two EMG variables and one lip pressure variable). The mean values of the two recordings of the control group were used in the further analyses. The random errors of the method were for the majority of the variables somewhat smaller than those found in children (Thüer et al. 1985).

\section{Biometric recordings}

From profile cephalograms, the same variables as were used by Thüer et al. (1985) and Thüer and Ingervall (1986) to describe the morphology of the face, the dentition and the lips were measured.

Overjet and overbite were determined by the method of Lundström (1948) from dental casts, which were also used to ascertain the Angle class.

\section{Statistical methods}

Systematic differences between the duplicate determinations were tested with a paired $t$-test. The random errors $\left(\mathrm{s}_{\mathrm{i}}\right)$ were calculated with the formula $s_{i}=\sqrt{ }\left(\Sigma \mathrm{d}^{2} / 2 \mathrm{n}\right)$, where $\mathrm{d}$ is the difference between the two determinations. Differences between the three groups were tested with the Mann-Whitney U-test and differences within the groups with Wilcoxon's matched-pairs signed-ranks test.

\section{Results}

The lip strength in the three groups is given in Table 2. There was no difference in the Pomvalues between the three groups. The lip pressure during the various functions studied is shown in Table 3 . There were no significant differences between the three groups in lip pressure in the rest position or during chewing. Only one significant difference was found during the speech recording; the lower lip pressure was lower $(0.01<\mathrm{P}<0.05)$ for the clarinetists than for the

Table 3 Median and range (in $\mathrm{g} / \mathrm{cm}^{2}$ ) of the pressure recorded at the lips and in the modiolus region in various lip functions.

\begin{tabular}{lcccccc}
\hline & \multicolumn{2}{l}{ Trumpeters } & \multicolumn{2}{l}{ Clarinetists } & \multicolumn{2}{l}{ Controls } \\
\cline { 2 - 5 } & Median & Range & Median & Range & Median & Range \\
\hline Rest & & & & & & \\
Upper lip & 2.8 & $-3.8-5.9$ & 1.1 & $-1.6-7.8$ & 0.5 & $-1.9-5.8$ \\
Modiolus & 3.9 & $0.5-11.2$ & 4.9 & $0.6-12.8$ & 2.9 & $0.0-6.2$ \\
Lower lip & 0.6 & $-2.2-22.8$ & 0.8 & $-1.7-7.7$ & 4.0 & $-3.3-10.7$ \\
Chewing opening phase & & & & & & \\
Upper lip & 25 & $10-66$ & 23 & $12-53$ & 27 & $13-60$ \\
Modiolus & 41 & $8-118$ & 30 & $17-159$ & 35 & $19-59$ \\
Lower lip & 144 & $18-360$ & 128 & $62-328$ & 161 & $54-464$ \\
Chewing closing phase & & & & & & \\
Upper lip & 25 & $7-51$ & 18 & $6-43$ & 20 & $12-66$ \\
Modiolus & 36 & $8-108$ & 30 & $11-146$ & 29 & $16-52$ \\
Lower lip & 79 & $14-376$ & 74 & $42-322$ & 121 & $42-524$ \\
Speech & & & & & & \\
Upper lip & 23 & $7-60$ & 24 & $7-71$ & 30 & $6-62$ \\
Modiolus & 57 & $23-85$ & 45 & $24-204$ & 40 & $20-181$ \\
Lower lip & 30 & $3-163$ & 22 & $15-84$ & 38 & $23-74$ \\
Simulated playing & & & & & & \\
Upper lip & 69 & $7-243$ & 51 & $9-200$ & & \\
Modiolus & 111 & $48-254$ & 66 & $8-219$ & & \\
Lower lip & 47 & $8-111$ & 32 & $16-207$ & & \\
\hline
\end{tabular}


Table 4 Number of individuals with negative resting lip pressures.

\begin{tabular}{llll}
\hline & Trumpeters & Clarinetists & Controls \\
\cline { 2 - 4 } Upper lip & 2 & 3 & 5 \\
Lower lip & 3 & 5 & 2 \\
\hline
\end{tabular}

controls. There was no significant difference in lip pressure between the trumpeters and the clarinetists during simulated playing.

In the group of clarinetists, the resting lip pressure measured at the modiolus was higher $(0.001<\mathrm{P}<0.01)$ than the lower lip pressure, and in the control group the upper lip resting pressure was lower $(0.01<\mathrm{P}<0.05)$ than the modiolus and lower lip pressures. No such significant differences were found in the trumpeters. In all three groups, there were some individuals with negative upper or lower lip resting pressures (Table 4) but none with a negative pressure in the modiolus region.

The distribution of the pressure during chewing was similar in all three groups, the highest pressure being recorded at the lower lip, followed by the modiolus region.

The pressure in the speech test was rather similar at all three places of measurement in the control group while in the two groups of musicians the pressure tended to be higher in the modiolus region. In the group of trumpeters, there was a significant $(P<0.001)$ difference between the upper lip and the modiolus and in the group of clarinetists between the lower lip and the modiolus $(0.001<\mathrm{P}<0.01)$.

The pressures measured during simulated playing are not representative of the pressures recorded during the actual playing of the instruments. The pressures measured during playing were as a rule considerably greater than those recorded during simulation (Table 5). As for the other pressures measured, the range of the values recorded is impressive.

Table 5 Median and range (in $\mathrm{g} / \mathrm{cm}^{2}$ ) of the pressure recorded during playing of the instrument.

\begin{tabular}{lrrlrr}
\hline & \multicolumn{2}{c}{ Trumpeters } & \multicolumn{2}{c}{ Clarinetists } \\
& Median & \multicolumn{1}{c}{ Range } & Median & \multicolumn{1}{c}{ Range } \\
\hline Upper lip $(\mathrm{n}=4)$ & 524 & $220-866$ & 121 & $88-170$ \\
Modiolus $(\mathrm{n}=4)$ & 86 & $44-170$ & 125 & $104-677$ \\
Lower lip $(\mathrm{n}=4)$ & 188 & $105-595$ & 229 & $172-278$ \\
\hline
\end{tabular}

Table 6 Median value (in $\mu \mathrm{V}$ ) of lip muscle activity in the rest position and during chewing and speech.

\begin{tabular}{|c|c|c|c|}
\hline & Trumpeters & Clarinetists & Controls \\
\hline \multicolumn{4}{|l|}{ Rest } \\
\hline Upper lip & 1.6 & 1.2 & 1.3 \\
\hline Lower lip & 1.3 & 1.6 & 1.5 \\
\hline \multicolumn{4}{|c|}{ Chewing opening phase } \\
\hline Upper lip & 139 & 169 & 125 \\
\hline Lower lip & 287 & 262 & 223 \\
\hline \multicolumn{4}{|c|}{ Chewing closing phase } \\
\hline Upper lip & 108 & 126 & 103 \\
\hline Lower lip & 189 & 163 & 163 \\
\hline \multicolumn{4}{|l|}{ Speech } \\
\hline Upper lip & 137 & 151 & 148 \\
\hline Lower lip & 140 & 139 & 125 \\
\hline
\end{tabular}

The lip muscle activity during the recordings of the lip pressure is shown in Table 6. The mean values of the median activity during the three pressure recordings (upper and lower lips and modiolus) are given in the Table.

There was only one significant difference between the groups. The upper lip activity in the opening phase of the chewing cycle during recording of the upper lip pressure was greater in the clarinetists than in the control group $(0.01<\mathrm{P}<0.05)$. Otherwise, the lip activity was very similar in the three groups, as is evident from Table 6 . Among the 28 biometric variables tested, only one showed a significant difference between groups. Thus, in the trumpeters, the lower lip covered on average only $2.2 \mathrm{~mm}$ of the upper incisors, compared to $3.6 \mathrm{~mm}$ in the control group $(0.01<\mathrm{P}<0.05)$.

\section{Discussion}

The errors of the method used for the recording of lip pressure and lip muscle activity, evaluated in the control group, were generally smaller than those previously found in the recordings in children (Thüer et al. 1985). The intra-individual variations in the values recorded are likely to be of a mainly biological nature and not due to the method of recording per se (Luffingham 1968, Thüer et al. 1985). The intra-individual variations are presumably the same in all three groups studied and should therefore not preclude comparison between them.

The lip strength of the subjects studied was considerably greater than in previous studies of 
children where the same method was used (Ingervall and Janson 1981, Owman-Moll and Ingervall 1984, Thüer and Ingervall 1986). In unselected children around 10 years of age, the Pom-value was found to be on average 173$210 \mathrm{~g}$ and to be correlated with age (Ingervall and Janson 1981, Thüer and Ingervall 1986). It is thus not surprising that the lip strength was higher in this group of adults. More interesting is the lack of difference between the three groups studied. The intensive use of the lips by the musicians has evidently not resulted in an increased lip strength, although this can be accomplished in children with incompetent lips by training with an oral screen (Owman-Moll and Ingervall 1984). It may be that such training is only possible in growing individuals or that the type of exercise is decisive.

The average pressure from the lips on the teeth in the rest position was the same in the present subjects as in children (Thüer et al. 1985, Thüer and Ingervall 1986) when recorded at the modiolus but was smaller at the lower lip and in the groups of clarinetists and controls also at the upper lip. Despite the increased lip strength of the present subjects in comparison with children, the pressure from the lips on the teeth thus tends to be lower. This confirms earlier findings of the independence of lip strength and lip pressure (Thüer and Ingervall 1986). The observations of the lip muscle activity in the rest position, parallel those for the lip pressure, with smaller values in the present groups than in children (Thüer $e t$ al. 1985).

The lip pressure during chewing tended to be smaller in this group than in children when recorded at the upper lip and in the modiolus region but was the same when recorded at the lower lip. The lip muscle activity during chewing closely paralleled that found in children (Thüer et al. 1985, Thüer and Ingervall 1986).

Different types of electrodes were, however, used in this investigation and in the studies of children, where the recordings were made with surface electrodes.

It is interesting that the pronunciation of the bilabial explosive ' $p$ ' resulted in the same amount of pressure from the upper lip on the teeth and from the modiolus even greater than was produced during chewing. The lower lip, however, was more active during chewing. The upper lip muscle activity was equally great during speech and chewing.
The results of the recordings of lip strength, pressure from the lips on the teeth and lip muscle activity show no effect of the wind instrument playing, either in comparison with the present control group or compared with children studied earlier. The claims by Parker (1957) and Herman (1981) that wind instrument playing develops and increases the tonicity of the lip muscles could thus not be substantiated.

The pressure recorded from the upper lip in this study during the playing of the trumpet corresponds very closely to that found by Engelman (1965). The pressure during the playing of the clarinet was, however, smaller in the present study than in that of Engelman (1965). This difference is probably due to methodological differences. Engelman used an oral shield in the upper vestibular fold for his recordings. This shield probably extended more from the teeth than the mouthpiece used in the present investigation. The upper lip was therefore more extended in the study of Engelman, which would influence the pressure recorded during the playing of the clarinet but not during the playing of the trumpet.

The pressures recorded during playing of the instrument were considerably greater than those found during both chewing and speech. Despite this, no effect on the dentition was found. All three groups were rather similar with respect to facial and bite morphology. This is in contrast to other reports where the playing of wind instruments has been shown to produce minor changes of the incisor relationships (Gualtieri 1979, Herman 1981). An explanation may be that professional musicians, like the subjects studied, often play several wind instruments, the influence of which on the dentition may be in different directions. It must also be taken into consideration that the groups studied were small and hence did not reveal possible small morphological differences between them.

In conclusion, this study of two groups of professional musicians playing two different instruments revealed no difference between them, or in comparison with a control group, regarding lip morphology, lip strength, lip muscle activity or pressure from the lips on the teeth during natural functions in spite of intensive use of the lips in wind instrument playing. This shows that lip muscle exercises, in order to be effective, must be specifically directed towards a certain goal. Whether such exercises will change 
the pressure from the oro-facial soft tissues on the teeth still remains to be proven.

\section{Acknowledgement}

This study was supported by Schweizerischer Nationalfonds zur Förderung der wissenschaftlichen Forschung (Grant Nr. 3.832-0.83).

\section{Address for correspondence}

Dr Urs Thüer

Klinik für Kieferorthopädie

Freiburgstrasse 7, CH-3010 Bern

Switzerland

\section{References}

Ahlgren J 1967 An intercutaneous needle electrode for kinesiologic EMG studies. Acta Odontologica Scandinavica 25: $15-19$

Engelman J 1965 Measurement of perioral pressures during playing of musical wind instruments. American Journal of Orthodontics 51: 856-864

Gualtieri P 1979 May Johnny or Janie play the clarinet? American Journal of Orthodontics 76: 260-276

Herman E 1981 Influence of musical instruments on tooth positions. American Journal of Orthodontics 80: 145-155
Ingervall B, Janson T 1981 The value of clinical lip strength measurements. American Journal of Orthodontics 80: 496-507

Ingervall B, Eliasson G-B 1982 Effect of lip training in children with short upper lip. Angle Orthodontist 52: 222233

Luffingham J K 1968 Pressure exerted on teeth by the lips and cheeks. Transactions British Society for the Study of Orthodontics 54:103-106

Lundström A 1948 Tooth size and occlusion in twins. Basle, Switzerland, S. Karger

Owman-Moll P, Ingervall B 1984 Effect of oral screen treatment on dentition, lip morphology, and function in children with incompetent lips. American Journal of Orthodontics 85: 37-46

Parker J 1957 The Alameda instrumentalist study. Amcrican Journal of Orthodontics 43: 399-415

Posen A L 1972 The influence of maximum perioral and tongue force on the incisor teeth. Angle Orthodontist 42: 285-309

Posen A L 1976 The application of quantitative perioral assessment to orthodontic case analysis and treatment planning. Angle Orthodontist 46: 118-143

Thüer U, Janson T, Ingerall B 1985 Application in children of a new method for the measurement of forces from the lips on the teeth. European Journal of Orthodontics 7: 63-78

Thüer U, Ingervall B 1986 Pressure from the lips on the teeth and malocclusion. American Journal of Orthodontics 90 : 234-242 